\section{Does use of 'non-trial' cessation support help explain the lack of effect from offering NRT to quitline callers in a RCT?}

\section{INTRODUCTION}

Quitlines help smokers to stop but few studies have explored how behavioural and medicinal interventions can be optimally delivered via this route. ${ }^{1}$ One of these was the PORTSSS trial, which found that offering free nicotine replacement therapy (NRT) vouchers did not increase cessation rates compared with no offer. ${ }^{2}$ It also found that a 'proactive', more intensive call regime from/to clients did not improve cessation rates over 'usual care'. Was it possible that participants who did not receive a voucher for NRT sought out and used other forms of cessation support, which minimised any effect of receiving the NRT voucher? Use of 'non-trial' support varied across PORTSSS trial intervention groups and, in this analysis, we sought to determine whether or not use of this substantially affected trial findings.

\section{METHODS}

Our secondary analysis included all 2591 randomised participants of the PORTSSS trial. PORTSSS was a randomised controlled trial (RCT) of an English, government-funded quitline, comparing two forms of behavioural support, with and without the offer of a free NRT voucher using a parallel-group, factorial $2 \times 2$ design. Non-trial support used by participants included 'over the counter' NRT $(\mathrm{n}=498 ; 19.2 \%)$, NRT from health professionals (479; 18.5\%), bupropion (37; $1.4 \%)$, varenicline $(165 ; 6.4 \%)$, NHS stop smoking service support $(125 ; 4.8 \%)$, NHS one-to-one therapy $(221 ; 8.5 \%)$ and a non-NHS quitline $(40 ; 1.5 \%)$; any support $(978 ; 37.7 \%)$. Binary variables were created for each support type with recipients coded as 1 and non-recipients as 0 . We used the same multivariable regression model as in the original trial analysis with the effect of treatment group adjusted for age, gender, age of finishing education and heaviness of smoking, and then additionally adjusted for each of the binary indicators of use of non-trial support to assess whether this altered the effect of treatment.

\section{RESULTS}

A comparison of the two adjusted models (table 1) shows little difference to the trial findings with respect to the primary outcome, prolonged cessation at 6 months (trial model OR $0.86,95 \%$ CI 0.7 to 1.06 ; additional model OR $0.84,95 \%$ CI 0.66 to $1.07)$ or any of the secondary outcomes, irrespective of whether self-reported or validated smoking outcomes are used.

\section{DISCUSSION}

To our knowledge, this is the first analysis to investigate the effect of additional cessation support on the impact of free NRT provision from a quitline. The findings suggest that use of such support does not explain the negative PORTSSS trial findings with respect to NRT. We identified only one other paper investigating associations between quitline outcomes and use of other forms of support ${ }^{3}$; it found that smokers who had used other types of cessation support prior to quitline enrolment were more likely to subsequently stop smoking with quitline help. Little is known about the relative contributions of quitline and nonquitline support to smoking cessation; monitoring and evaluating the relationship of 'non-trial' cessation support to outcomes in future quitline studies is important.

\section{Key messages}

- The PORTSSS trial found that offering free NRT vouchers to quitline clients did not improve cessation rates.

- Use of other cessation support used outside the trial did not explain the negative PORTSSS trial findings with respect to NRT.

\section{Graeme Docherty, ${ }^{1}$ Sarah Lewis, ${ }^{1}$ Andy McEwen, ${ }^{2}$ Linda Bauld, ${ }^{3}$ Tim Coleman ${ }^{4}$}

${ }^{1}$ Department of Epidemiology and Public Health, UK Centre for Tobacco Control Studies, University of Nottingham, Nottingham, UK

${ }^{2}$ Department of Epidemiology and Public Health, Cancer Research UK Health Behaviour Research Centre, UK Centre for Tobacco Control Studies, University College London, London, UK

Table 1 Smoking cessation outcomes in relation to nicotine replacement therapy (NRT)

\begin{tabular}{|c|c|c|c|c|c|c|}
\hline & $\begin{array}{l}\text { Total } \\
\mathrm{N}=2591\end{array}$ & $\begin{array}{l}\text { No NRT } \\
\mathrm{N}=1296\end{array}$ & $\begin{array}{l}\text { NRT } \\
\mathrm{N}=1295\end{array}$ & $\begin{array}{l}\text { Unadjusted OR } \\
\text { (95\% Cl; } p \text { value) }\end{array}$ & $\begin{array}{l}\text { Adjusted } O R^{*} \\
\text { (95\% Cl; } p \text { value) }\end{array}$ & $\begin{array}{l}\text { Adjusted ORt } \\
\text { (95\% Cl; p value) }\end{array}$ \\
\hline \multicolumn{7}{|l|}{ Outcomes at 6 months, $\mathrm{n}(\%)$} \\
\hline $\begin{array}{l}\text { Prolonged cessation (inc. questionnaire data) } \\
\text { (primary outcome) }\end{array}$ & $490(18.9)$ & $261(20.1)$ & $229(17.7)$ & $\begin{array}{l}0.85(0.70 \text { to } 1.04 ; \\
p=0.11)\end{array}$ & $\begin{array}{l}0.86(0.70 \text { to } 1.06 ; \\
p=0.16)\end{array}$ & $\begin{array}{l}0.84(0.66 \text { to } 1.07 ; \\
p=0.17)\end{array}$ \\
\hline Carbon monoxide validated prolonged cessation & $207(8.0)$ & $122(9.4)$ & $85(6.6)$ & $\begin{array}{l}0.67(0.50 \text { to } 0.90 ; \\
p=0.008)\end{array}$ & $\begin{array}{l}0.65(0.48 \text { to } 0.88 ; \\
p=0.005)\end{array}$ & $\begin{array}{l}0.63(0.45 \text { to } 0.86 ; \\
p=0.004)\end{array}$ \\
\hline Self-reported cessation for $\geq 7$ days & $531(20.5)$ & $283(21.8)$ & $248(19.1)$ & $\begin{array}{l}0.85(0.70 \text { to } 1.03 ; \\
p=0.09)\end{array}$ & $\begin{array}{l}0.85(0.70 \text { to } 1.04 ; \\
p=0.13)\end{array}$ & $\begin{array}{l}0.85(0.67 \text { to } 1.07 ; \\
p=0.17)\end{array}$ \\
\hline Carbon monoxide validated cessation for $\geq 7$ days & $200(7.7)$ & $119(9.2)$ & $81(6.2)$ & $\begin{array}{l}0.66(0.49 \text { to } 0.88 ; \\
p=0.006)\end{array}$ & $\begin{array}{l}0.64(0.47 \text { to } 0.87 ; \\
p=0.004)\end{array}$ & $\begin{array}{l}0.62(0.45 \text { to } 0.86 ; \\
p=0.004)\end{array}$ \\
\hline Reported cessation for $\geq 3$ months & $401(15.5)$ & $216(16.6)$ & $185(14.3)$ & $\begin{array}{l}0.83(0.67 \text { to } 1.03 ; \\
p=0.09)\end{array}$ & $\begin{array}{l}0.84(0.67 \text { to } 1.05 ; \\
p=0.14)\end{array}$ & $\begin{array}{l}0.86(0.66 \text { to } 1.10 ; \\
p=0.23)\end{array}$ \\
\hline Reports one or more quit attempts lasting $>24 \mathrm{~h} \dagger$ & $594(22.9)$ & $289(22.3)$ & $305(23.5)$ & $\begin{array}{l}1.07(0.88 \text { to } 1.28 ; \\
p=0.49)\end{array}$ & $\begin{array}{l}1.05(0.86 \text { to } 1.27 ; \\
p=0.60)\end{array}$ & $\begin{array}{l}1.15(0.88 \text { to } 1.50 ; \\
p=0.30)\end{array}$ \\
\hline Median (IQR) no. quit attempts reported & $2(1-3)$ & $2(1-4)$ & $2(1-3)$ & $\mathrm{n} / \mathrm{a}$ & $\mathrm{n} / \mathrm{a}$ & $\mathrm{n} / \mathrm{a}$ \\
\hline \multicolumn{7}{|l|}{ Outcomes at 1 month, $\mathrm{n}(\%)$} \\
\hline Prolonged cessation since quit date & $1040(40.1)$ & $520(40.1)$ & $520(40.1)$ & $\begin{array}{l}0.99(0.85 \text { to } 1.16 ; \\
p=0.93)\end{array}$ & $\begin{array}{l}1.01(0.86 \text { to } 1.19 ; \\
p=0.88)\end{array}$ & $\begin{array}{l}1.00(0.80 \text { to } 1.26 ; \\
p=0.96)\end{array}$ \\
\hline Reported cessation for $\geq 7$ days & $831(32.0)$ & $417(32.2)$ & $414(32.0)$ & $\begin{array}{l}0.98(0.83 \text { to } 1.16 \\
p=0.85)\end{array}$ & $\begin{array}{l}0.99(0.84 \text { to } 1.18 ; \\
p=0.97)\end{array}$ & $\begin{array}{l}0.97(0.77 \text { to } 1.22 ; \\
p=0.80)\end{array}$ \\
\hline
\end{tabular}

*Adjusted for age, gender, educational level and heaviness of smoking index; 2397 cases included in adjusted analyses.

tAdditionally adjusted for all forms of non-trial support. 
${ }^{3}$ UK Centre for Tobacco Control Studies, Institute of Social Marketing, University of Stirling, Stirling, UK ${ }^{4}$ Division of Primary Care, UK Centre for Tobacco Control Studies and NIHR School for Primary Care Research, University of Nottingham, Queen's Medical Centre, Nottingham, UK

Correspondence to Graeme Docherty, Department of Epidemiology and Public Health, UK Centre for Tobacco Control Studies, University of Nottingham, C100, Clinical Sciences Building, City Hospital, Hucknall Road, Nottingham NG5 1PB, UK; graeme.docherty@nottingham.ac.uk

Acknowledgements We are grateful to Dr Coral Gartner, University of Queensland who provided the idea for the analysis.

Contributors GD conducted the analysis and led writing of the manuscript. TC assisted with the study design and advised on the analysis. SL supervised the analysis. All authors were involved in the review of the manuscript prior to submission.

Funding The work was undertaken by the UK Centre for Tobacco Control Studies, a UKCRC Public Health Research Centre of Excellence. Funding from British Heart Foundation, Cancer Research UK, Economic and Social Research Council, Medical Research Council, the National Institute for Health Research, under the auspices of the UK Clinical Research Collaboration, is gratefully acknowledged. The PORTSSS trial was funded by the Department of Health in England.

Competing interests TC has, within the last 5 years, spoken at two conferences which were organised and funded by Pierre Fabre Laboratories, a company which manufactures NRT products. He has also advised a public relations company on the (lack of) evidence for using Nicobloc as an aid for smoking cessation. AM receives a personal income from Cancer Research UK via University College London. He has received travel funding, honorariums and consultancy payments from manufacturers of smoking cessation products (Pfizer Ltd, Novartis UK and GSK Consumer Healthcare Ltd) and hospitality from North51 who provide online and database services. He also receives payment for providing training to smoking cessation specialists; receives royalties from books on smoking cessation and has a share in a patent of a nicotine delivery device. LB is vice-chair of the Cancer Research UK Tobacco Advisory Group and serves as Scientific Adviser to the Department of Health on tobacco control. GD and SL have no conflicts of interest to declare.

Patient consent Obtained.

Ethics approval The PORTSSS trial received a favourable opinion by Leicestershire, Northamptonshire and Rutland Research Ethics Committee (08/H0406/164).

Provenance and peer review Not commissioned; externally peer reviewed.

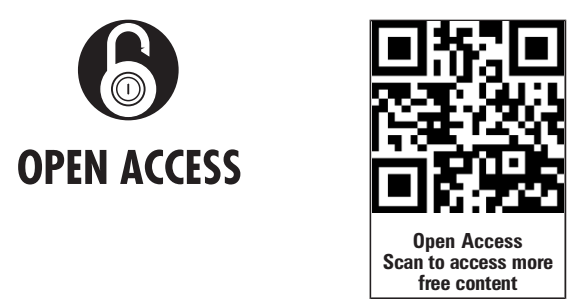

Open Access This is an Open Access article distributed in accordance with the terms of the Creative Commons Attribution (CC BY 3.0) license, which permits others to distribute, remix, adapt and build upon this work, for commercial use, provided the original work is properly cited. See: http:// creativecommons.org/licenses/by/3.0/

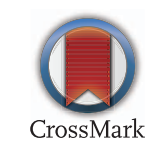

To cite Docherty G, Lewis S, McEwen A, et al. Tob Control 2014;23:524-525.

Accepted 2 June 2013

Published Online First 23 July 2013

Tob Control 2014;23:524-525.

doi:10.1136/tobaccocontrol-2013-051107

\section{REFERENCES}

1 Stead LF, Perera R, Lancaster T. A systematic review of interventions for smokers who contact quitlines. Tob Control 2007;16(Suppl 1):i3-8.

2 Ferguson J, Docherty G, Lewis S, et al. Effect of offering different levels of support and free nicotine replacement therapy via an English national telephone quitline: randomised controlled trial. BMJ 2012;344: e1696.

3 Helgason AR, Tomson T, Lund KE, et al. Factors relating to abstinence in a telephone helpline for smoking cessation. Eur J Pub Health 2004;14:306-10. 